\title{
Learning to face global food challenges through tourism experiences
}

\author{
Giovanna Bertella and Benjamin Vidmar
}

Giovanna Bertella is based at University of Tromsø, Tromsø, Norway.

Benjamin Vidmar is based at Polar Permaculture Solutions, Longyearbyen, Norway.

\author{
Received 14 January 2019 \\ Revised 4 June 2019 \\ Accepted 5 June 2019 \\ (C) Giovanna Bertella and \\ Benjamin Vidmar. Published in \\ Journal of Tourism Futures. \\ Published by Emerald Publishing \\ Limited. This article is published \\ under the Creative Commons \\ Attribution (CC BY 4.0) licence. \\ Anyone may reproduce, distribute, \\ translate and create derivative \\ works of this article (for both \\ commercial and non-commercial \\ purposes), subject to full attribution \\ to the original publication and \\ authors. The full terms of this \\ licence may be seen at http:// \\ creativecommons.org/licences/by/ \\ 4.0/legalcode
}

\begin{abstract}
Purpose - The purpose of this paper is to provoke reflections on the potential contribution of food tourism experiences to achieving the sustainable development goals for eradicating hunger and malnutrition.

Design/methodology/approach - In line with the creative analytic practice in scientific inquiry, this study develops and discusses a futuristic scenario inspired by a factual company. The case is based on ideas derived from studies on educational and food tourism and entrepreneurship, more precisely ecopreneurship. Findings - Food tourism can offer an opportunity for discussing food challenges in the context of ideas and projects to alleviate hunger and malnutrition. This study shows that imagining such possibilities and projects is challenging because of the complexity of the issue.

Practical implications - This study suggests that despite some limitations, educational food tourism experiences might go well beyond the issues of regional development, localism and authenticity. Practitioners, including tourism entrepreneurs and private and public food and tourism organisations, might be essential to exploring alternative food tourism futures in ways that truly contribute to urgent global challenges.

Originality/value - The value of this paper lies in the use of a scenario to imagine and to reflect on the future of food tourism in relation to the global challenges of hunger and malnutrition. The paper suggests that the ideas from tourism studies and ecopreneurship can offer interesting perspectives on future developments in the sector.

Keywords Sustainability, Food tourism, Sustainable development goals, Ecopreneurship, Educational tourism, Transformative experiences
\end{abstract}

Paper type Research paper

\section{Introduction}

This study presents and discusses a futuristic scenario about food, tourism and sustainability. As was highlighted by Luks (2014), attempts to promote sustainability might need not only measurements and models but also engaging narratives. The goal of this study is to provide such a narrative. This is in line with the suggestions of Bina et al. (2017) in their review of fiction in relation to the global goals identified in the European policy since the development of the "2007 Green Paper" on research areas. Imagining the future through fiction can be useful for reflecting on and framing global challenges; consequently, it can be determinative in the search for feasible solutions and the consideration of their effects.

This study builds on two reflections. The first is the key role of food in the United Nations (UN) "2030 Agenda for Sustainable Development" (United Nations, 2015). Food is relevant to Sustainable Development Goal 1, which is about ending poverty, and Goal 3, which deals with health. Moreover, it is the focus of Goal 2: "End hunger, achieve food security and improved nutrition and promote sustainable agriculture" (United Nations, 2015, p. 14). Other aspects of this goal include ensuring food access, developing sustainable food production systems and resilient agricultural practices, strengthening the capacity for adaptation to climate change and extreme weather, maintaining the genetic diversity of food sources and increasing investment and international cooperation.

The second reflection on which this study builds relates to two trends identified by Yeoman and McMahon-Beatte (2016). They concern the future of food tourism: food tourism as political 
capital and a visionary state. Food production and tourism have been important elements of many recent public policies and strategies because of their potential to create economic prosperity, to generate jobs opportunities and to develop specific geographical areas that are typically rural. The interrelation of food production and tourism activities has important political implications and can be viewed as a type of utopian vision. The latter was described by Yeoman and McMahon-Beatte (2016) as a shared project through which communities, producers, tourists and political groups shape a future on the basis of ideologies such as localism, authenticity and activism against globalisation.

On the basis of these reflections, this study poses the question: How will the food tourism experiences of the future contribute to the alleviation and subsequent eradication of hunger and malnutrition? It develops a futuristic scenario about the role of food tourism experiences in the management of the food-related challenges identified by the UN. This scenario can be viewed as a normative scenario developed on the basis of the authors' hopes about a preferred future. The study elaborates on the transformative potential of tourism experiences, specifically one type of educational tourism experience: the Grand Tour. This educational tourism experience is presented in the next section, together with the challenges identified in the scholarly literature related to food and food tourism. The main source of inspiration for the development of the futuristic scenario, a factual company located in the Arctic archipelago of Svalbard, Norway, is described. Its adoption of elements of entrepreneurship, more specifically ecopreneurship is analysed. The paper then presents the futuristic scenario with a discussion on potential problems. The conclusion reflects on food tourism experiences and their transformative potential for overcoming the challenges of imagining and, even more, implementing the changes needed for a better future.

\section{Educational potential and food tourism challenges}

\subsection{Educational potential of tourism experiences}

Several scholars have argued that tourism experiences might not only increase knowledge but also influence attitudes and values. In other words, tourism experiences can be transformative, i.e. contributing to the realisation of the ideal person who a tourist truly wants to be (Morgan, 2010; Coghlan and Gooch, 2011; Falk et al., 2012; Pine and Gilmore, 2013; Stone and Petrick, 2013). The Grand Tour is an example of such forms of educational tourism. The Grand Tour is the travel undertaken by upper class European youths in the seventieth and eighteenth centuries as part of their education (Towner, 1985). Such travel had the aim of exposing the European elite to various aspects of European culture. It was characterised by a romantic view of urban and rural landscapes, including attractions such as classical antiquities, renaissance treasures, picturesque scenery and wild nature. The major destinations were France, Switzerland and Italy. Towner (1985) has argued that many features of the Grand Tour can be useful for understanding today's tourism. It can be added that the Grand Tour can also be useful for imagining future tourism.

Inspired by the core idea of this form of tourism, this study reflects on the role of food tourism in the development of solutions for the urgent food-related challenges.

\subsection{Food tourism challenges in theory and practice}

Ellis et al. (2018) review the literature contributions about food tourism from 1994 to 2017 commenting on the various understandings and perspectives. In the literature, food tourism is understood as a sensory and cultural experience for tourists who are motivated by an interest in food, as well as an element of a destination's offer, often in relation to the authenticity of a place. Ellis et al. (2018) conclude that the management of food tourism needs to adopt an approach that combines the experiential aspect of such form of tourism as well as issues relevant to sustainable food production and consumption.

De Jong et al. (2018) review the literature about food tourism across disciplines and, in line with Ellis et al. (2018), note that food tourism tends to be investigated and discussed in relation to the issues surrounding regional development, localism and authentic experiences. 
Moreover, De Jong et al. (2018) highlight a lack of engagement in critical approaches, including sustainability. Based on both reviews and as observed by Higgins-Desbiolles (2010), the reflection about the role of food tourism in an increasingly vulnerable and stressed environment and its possible re-orientation towards alternative systems of production and consumption are very limited.

A similar situation has been noted regarding the traditional profile of the television shows, films and documentaries dealing with food. This phenomenon has become relevant for food tourism through the destination branding and cooking classes for tourists (Stewart et al., 2008; Lindenfeld, 2010). It has been noted that celebrity chefs can be strong influencers. Food shows often fail to represent the problematic aspects of the food system; instead, they support the commodification and fetishization of food (Caraher et al., 2000; Lindenfeld, 2010). Only recently has a shift occurred in food documentaries. Several films, e.g. Food Inc., have encouraged consumers to act as political agents and to make more sustainable choices (Lindenfeld, 2010). Such a shift is also desirable in the food tourism scholarly literature; however, this has not yet occurred.

Moskwa et al. (2015) have noted that few practitioners engage in activities that support food justice and sustainability. They referred to "pioneers", often lifestyle entrepreneurs, who are engaged in and develop offerings based on sustainable practices that respect the environment and contribute to the wellbeing of their communities. They suggest that food can be an important medium for change and that food tourism should be reconsidered in these terms.

Based on these considerations about the limitations of food tourism theory and practice and in accord with potentials presented in Section 2.1, this study understands food tourism as an educational experience potentially relevant to sustainability. Thus, the intended contribution is both in relation to the scholarly literature and the practice of food tourism.

Thinking about the future of tourism, Wright (2018) explores animal cloning in luxury food tourism. He views such technology as a possible path to meet the needs and desires of future societies. He imagines how a luxury restaurant might be in 2070. In this futuristic scenario, tourists can pre-order dishes that will be prepared using cloned animals that have been extinct in the wild for decades, with the result of exclusive unforgettably tasty experiences.

While Wright's study concerns wealthy tourists and their desires for food experiences, this study concerns how tourism experiences might contribute to food-related sustainable goals. The focus is on plant-based food because vegetarianism and meat reduction are the diets that can contribute the most to sustainability in terms of the reduction of $\mathrm{CO}_{2}$-emissions, acidification, land use and biodiversity damage (Martin and Brandão, 2017).

The following section presents the case of a factual company. It provides an example of an increased engagement in food tourism based on sustainability, especially the production of safe, fresh and nutritional food. Such a company constitutes the main source of inspiration for developing a scenario about the food tourism experience of the future.

\section{Re-thinking food tourism: Arctic veggies and food ecopreneurship}

\subsection{Polar Permaculture Solutions}

The Norwegian town of Longyearbyen is located in the main island in the Svalbard archipelago $\left(78^{\circ} \mathrm{N}\right)$. Together with the small settlement of $\mathrm{Ny}$-Ålesund, it has 2,310 inhabitants (SSB, 2018). Longyearbyen is home to Polar Permaculture Solutions, founded in 2015 by a chef from Ohio. The company uses a geodesic dome greenhouse, a microgreens laboratory and sustainable composting systems. It is the only local producer of fresh foods, such as organic microgreens, lettuce, herbs and sprouts, on Svalbard. The company's vision is articulated in four points (www.polarpermaculture.com/):

1. nourish our community: the company provides fresh food to local stores, hotels, restaurants and private residences;

2. create local resources: the company reduces imports to a minimum and strives to reclaim the island's self-sufficient power;

PAGE $170 \mid$ JOURNAL OF TOURISM FUTURES $\mid$ VOL. 5 NO. 22019 
3. sustain a circular economy: the company uses composting red worms to break down and repurpose waste into a natural fertilizer, avoiding other methods such as the waste dumping directly into the sea or flown to Sweden for incineration; and

4. build global solutions: the company is a living example that innovative agriculture technology and systems can be successfully applied everywhere in the world.

With 20 years of international experience as a chef, the Polar Permaculture Solutions founder first visited Svalbard in 2007. After some years as the head chef at the local pub, he considered growing fresh greens. He intended to create a circular economy in which biological waste from food production could be captured and converted into heat, electricity and fertilizer that could be used to grow more food.

Through his tenacity and enthusiasm, his innovative ideas took shape, and in 2015, Polar Permaculture Solutions was established. Financial support was provided by state-owned Innovation Norway and the Svalbard Environmental Protection Fund for the initial phases of the project. Additional support will be provided for future development, including the scaling up of the reuse of waste to include all of Longyearbyen.

In the meanwhile, two important projects have begun. In 2015, the company added two tourism products: volunteer tourism and guided tours. In both cases, the experiences have so far been very positive. Many people have shown interest in working for or visiting and learning more about permaculture in general and the company in particular. This is evident from the TripAdvisor reviews: 30 out of 33 reviews were excellent. The comments have included: "the tour offers a fascinating insight into a project with exceptionally far reaching [sic.] implications if it becomes a viable and sustainable production site"; "if you are interested in permaculture, individual independent agriculture, organic and healthy food, you should certainly visit the place"; and "[the project] seems to be particularly important in this town, and I feel it is also important also [sic.] globally".

Since 2016, Polar Permaculture Solutions has led a local school project in which the children learn to grow vegetables and to compost waste. The Polar Permaculture Solutions founder is one of the stewards of the Permaculture Collaborative Laboratory, an international network for the promotion of sustainable and healthy food practices around the world.

\subsection{Polar Permaculture Solutions thorough an entrepreneurship lens}

The Polar Permaculture Solutions case can be analysed by applying the idea of islands as innovation laboratories. It must be noted that in the human imagination, islands are often sites of fascination, as well as territories and metaphors (Baldacchino, 2013). Interestingly, among the descriptions of islands in the literature are "utopian and dystopian", "tourist meccas" and "ecological refugia" (Stratford, 2003, p. 495).

In his article "Islands as novelty sites", Godfrey Baldacchino made a compelling case for islands as "the quintessential sites for experimentation" to facilitate the exploration of new ideas. According to this view, islands can deliver "treasures", such as "powerful messages, bearing the fullness of new and vital noises" (Baldacchino, 2007, pp. 170-71). Moreover, islands can be laboratories for developing solutions to global challenges, and these solutions can be transferred to other locations for large-scale implementation (Greenhough, 2006; Baldacchino, 2005; Kelman et al., 2015).

The latter consideration can be considered in relation to the potential removal of various constraints that limit or prevent possible societal change (Steyaert and Hjorth, 2006; Calás et al., 2009; Rindova et al., 2009; Haugh and Talwar, 2016). Dey and Mason (2018) have argued that some of the more difficult problems in entrepreneurship are the mental constructions based on limited shared narratives and images of how things are and how they could be. Overcoming such mental limitations can be empowering by enabling the envisioning of alternative realities, including sustainable solutions to urgent problems (Shepherd and Patzelt, 2011).

Narratives can be liberating. The story of this Svalbard company can inspire approaches to food production to facilitate the achievement of the UN sustainability goals. Specifically, the 
Polar Permaculture Solutions founder can be considered an ecopreneur, i.e. an entrepreneur who develops a new business based on sustainability principles (Schaltegger, 2002; Kirkwood and Walton, 2010). He exhibits several of the ecopreneurial characteristics identified in the literature. They are a strong commitment to specific idealistic values, an inner tension between making profits and acting in a "green" way and relatively strong relationships with the external environment (Walley and Taylor, 2002; Santini, 2017). Linnanen (2005) has described ecopreneurs as having an innate openness to social and ecological responsibilities and, ultimately, being relevant social change actors. These qualities apply to the Polar Permaculture Solutions founder and can be the inspiration for imagining a futuristic scenario.

\section{Imagining the future: food tourism in the coming decades}

\subsection{The construction of the fictional scenario}

This study relies on the use of creativity as a potentially fruitful way to think and to reflect (Richardson and St Pierre, 2005). As was briefly mentioned in the introduction, fiction as a mode of inquiry can be useful for deep explorations of phenomena. It is an engaging way to stimulate the imagination and critical thinking (Eisner, 1997; Banks and Banks, 1998; Phillimore and Goodson, 2004; Wilson and Hollinshead, 2015; Bina et al., 2017).

Moreover, fiction can facilitate the engagement of non-academicians in academic projects. This is an important aspect of the collaboration of the two authors of this paper (an academician and a practitioner, the Polar Permaculture Solutions founder). Such collaboration, characterised by a reciprocal respect for each other's expertise and a genuine concern for food-related issues, has been essential to developing and discussing the future scenario.

The process of developing a scenario about the future of food tourism followed some central ideas about scenario thinking and in particular normative scenario development, and is illustrated in Table I (Van Notten et al., 2003; Andreescu et al., 2013; Robertson and Yeoman, 2014; Yeoman and Postma, 2014).

The approach used in the scenario process design leaned strongly on qualitative knowledge and insights, interpreted on the basis of the authors' values and beliefs, and creatively adopted to imagine a preferred future. The description and analysis of this Svalbard company is the main source of inspiration as it illustrates the existing technology and the related possibility of growing food in extreme environments by applying circular economy principles. In order to develop a plausible scenario and identify weak signals, i.e. early signals of possible change, some information was gained consulting the following sources:

- the pathways to sustainability outlined by the Food and Agriculture Organization (FAO) of the United Nations (2018);

- the healthy diet report by the World Health Organization (2018); and

- the food grassroots movements (Holt Giménez and Shattuck, 2011).

Table I The process of the scenario development

Diagnosis and challenges relevant to food tourism Values and beliefs

The authors' vision about a Intuitive creative $\begin{array}{ll}\text { Polar Pemaculture } & \text { The authors' vision about a } \\ \text { Solutions } & \text { future without hunger and }\end{array}$ malnutrition

Reports (UN, FAO, The potential role of WHO) and scholarly ecopreneurship and literature (food educational tourism in tourism) relation to social change process: qualitative knowledge and insights, imagination

Dialogue between the co-authors (one academician and one practitioner)
Reflections on the visionary scenario

The fictional narrative is presented in three Identification of phases (from bad to worse; seeds of change; problematic ascpects

(1)

\section{0: food tourism as a transformative experience for social change) to engage the reader}

Dialogue between the co-authors (one academician and one practitioner) 
These sources were used to identify future challenges about food production and consumption and trends concerning social movements and business creation. In addition, the WHO source was used in relation to the importance to focus on plant-based food as particularly relevant to human health.

This study focusses on a scenario about a preferred future based on the authors' values and beliefs concerning the possible role of tourism and ecopreneurship in fighting global hunger and malnutrition and, therefore, it can be qualified as normative or visionary (Pritchard et al., 2011; Van Notten et al., 2003; Hurley, 2015). The scenario was developed in a narrative way and identifying three phases, with the intent to engage the reader in imagining a series of possible changes and outcomes (Eisner, 1997). Some reflections about the possible critical aspects of this utopian future emerged at the end of the developmental process. Considerations about these aspects are presented in Section 5.

\subsection{The evolution of food and food tourism}

4.2.1 From bad to worse. In 2030, the global food situation is extremely problematic. Different types of malnutrition are widespread. Undernourishment has started to increase again in several countries, and the health problems related to overweight and obesity are on the rise in rich societies. In 2015, food-related goals were inserted into the UN's sustainable development priorities. In 2019, the FAO released the following message:

The future of food is jeopardized by several trends that require a radical change of course: businessas-usual is no longer an option. All countries and social groups must commit to responsibility-sharing in implementing fundamental changes. In particular, those who can reasonably shoulder the costs involved in the necessary transformations have to provide support to those who need it and invest in new food production and distribution systems. (Adapted from FAO, 2018)

Despite the gravity of the situation and the urgency of this message, no government took any significant action that could lead to the necessary change. The situation has worsened, and in the 2020s, a worrying trend has emerged in those societies recognised by the FAO as being particularly responsible for guiding and supporting the change. In the rich societies, food consumption has moved in diametrically opposite directions from those recommended by the WHO (World Health Organization, 2018). Diets characterised by an increase in saturated fats, trans fats, sugar and animal products and a reduction in vegetables, fruits and legumes are popular.

In 2030, the commodification and fetishization of food is very evident. Food is no longer viewed as nutrition but as one of the many commodities through which consumers can gain status and affirm their egos with no concern for the health and ethical implications of their behaviour. A symbol of this trend is the emergence of chefs as role models and worldwide celebrities with enterprises that are admired and followed by the general public.

Food tourism mirrors these trends. Popular destinations have been developing into gastronomic theatres in which chefs play with food to entertain tourists. The foodie is a self-centred globetrotter seeking food experiences, such as food festivals involving competitive eating, food fights and sitophilia-oriented encounters.

4.2.2 Seeds of change. Despite the above-mentioned trends, some signs of change were identified as early as the 2010s (Holt Giménez and Shattuck, 2011). The global grassroots movement, which focuses on nutritional problems around the world, consolidated and assumed a technology-oriented profile. Ecopreneurs have been the engine of this shift. Strongly committed to change and very competent in new technology-based food production methods, ecopreneurs have identified islands at various latitudes as ideal locations for the laboratories for developing sustainable solutions for hunger and malnutrition.

By 2050, ecopreneurs are assuming the roles once filled by celebrity chefs. People around the world are enthusiastically following their enterprises, such as the production of greens in Svalbard and the cultivation of legumes and high-quality grains on the North Sentinel Island in the Bay of Bengal. 
4.2.3 2100: food tourism as a transformative experience for social change. Ecopreneurs are the new role models, and food tourism achieves its potential for social change. In 2100, the foodie trend assumes a new profile. In particular, young tourists travel to islandic food laboratories. At these destinations, food ecopreneurs, motivated by the ideals of justice and sustainability and a strong commitment to translating these ideals into their business practices, inspire tourists to think and to act differently to overcome the food-related challenges.

Such travel has become widespread, especially among the new international potential policy makers. Like the wealth seventieth- and eighteenth-century youths who travelled around Europe, new generations of travellers are visiting distant islands; however, their goal is to learn about food laboratories, food challenges and feasible solutions. While the heart of the old Grand Tour was the classical antiquities and Renaissance treasures in Europe, the new Grand Tours are centred around the innovation laboratories and charismatic lifestyle ecopreneurs around the world. Food tourism has truly become a force for change, and it is based on the value of global justice and the inspiring force of ecopreneurship.

\section{Reflections}

The scenario depicted in this paper offers hope for the future of food tourism. The potential for tourism as an educational and transformative experience and the possibilities offered by ecopreneurship are the bases for such hope. The scenario suggests that the food tourism could contribute substantially to overcoming the global food challenges. This might depend on the ideals and abilities of food and tourism ecopreneurs, and the support that they might receive from national and international organisations. Food tourism as described in this futuristic scenario provokes critical reflections on several aspects of the possible events and actions for realising some of the sustainable goals identified by the UN.

The first aspect concerns the location of the imagined food laboratories. In this scenario, these laboratories are located in isolated areas, specifically islands, around the world. It is reasonable to question the identification of these islands and the extent to which the interests of the local inhabitants would be considered before and after the establishment of such laboratories. The local inhabitants include humans and wildlife. For example, in the case of Svalbard, questions could be asked about the possible negative effects of an expansion of Polar Permaculture Solutions and the resulting increased attractiveness to tourists. For example, the polar bear population, already threatened by climate change and, occasionally, the presence of tourists, could experience further changes to their habitat (Descamps et al., 2017). The effects of such changes are unknown. If not well-managed, an extensive food laboratory that might attract additional tourists and employees could result in a higher number of close encounters and accidents. Another issue could be the survival of the animals, given the reduction of available place because of the growing number of residents and tourists.

A concern in the areas identified for the establishment of food laboratories would be the aboriginal populations. One of the islands mentioned as a site for future food laboratories in the scenario is the North Sentinel Island. It is one of the few remaining areas where an aboriginal population still lives, virtually untouched by modern civilisation. Sentinelese have no contact with the outside world. Of concern would be the fate of the Sentinelese if their island is identified as a possible location for a food laboratory. A risk is that the future Grand Tour could assume the profile of colonisation.

In sum, the establishment of the food laboratories described in the scenario might be at the expense of some humans and non-humans who might not benefit from the laboratories or the products. Thus, the islands used in the scenario and mentioned in the entrepreneurship literature could be considered metaphors. An alternative scenario could be based on food laboratories located in established urban areas, such as tunnels and rooftops. This might limit the design of tourism experiences in the style of the Grand Tour because the exotic component of travel would decrease. However, it could facilitate the development of a more environmentally friendly Grand Tour that reduces the distance travelled to the food laboratories and does not increase the human presence on relatively wild areas. 
Another aspect is elitism. In the traditional Grand Tour, only the members of wealthy families could have afforded to travel around Europe. In the future Grand Tour, the travellers might also be limited to the upper class, given the expense of getting to laboratories located on remote islands. This might lead to the reproduction of a class system in which only wealthy youths can have access to these educational experiences that could facilitate their becoming influential policy makers. Governments and international organisations should therefore provide support, e.g. grants, to make such educational tourism experiences available to talented youths regardless of their financial circumstances.

Similarly, governments and international organisations could play an important role by supporting the emergence of the technology-based food companies described as the tourist attractions of the future. The ecopreneurs in the scenario are role models for the tourists. Although the ecopreneurs' charisma might play an important role in how they are perceived, publicly financed promotional activities could be influential. The food-related activities of the sustainable enterprises presented in the scenario might require considerable funding. As in the Svalbard case, the accessibility to grants can be determinative.

Finally, elitism can be considered an assumption of this study and, specifically, the presented scenario, i.e. sustainability as a fundamentally anthropocentric approach to understanding and managing the future. In this sense, humans are considered the elites of the planet's life forms, which are viewed as resources for the present and future generations of humans. It is not the purpose of this paper to discuss the ethical assumptions and implications of this position. Nevertheless, it might be appropriate to reflect on the predominant role of sustainability in the discourse on the future of the planet. This has not received very much attention in tourism (Fennell, 2014; Bertella, 2019).

Thus, the final reflection concerns the potential of food tourism as an educational and transformative experience in the promotion of care and respect for all other forms of life. This might require imagination greater than that applied to the development of this scenario. The main point would be the shift from the widespread use of the sustainability approach to an alternative and less anthropocentric one. Although very challenging, this is possible with the application of the core components of ecopreneurship, i.e. competence, responsibility and creativity.

\section{Conclusion}

This study has posed the question of the contribution of food tourism experiences to the alleviation and eradication of hunger and malnutrition in the future. It was answered by the presentation of ideas from various streams of scholarly literature, in particular educational tourism, food tourism and entrepreneurship. Methodologically, this study adopted a creative approach, developing a fictional futuristic scenario inspired by a factual company. Such scenario and its discussion contribute to deepen the scholarly debate about food tourism experiences, going beyond the broadly investigated issues of authenticity, localism and regional development, and highlighting its potentials in relation to possible responses to global challenges.

The intention was to develop a utopian scenario based on the potential of food tourism as providing transformative experiences that are relevant to a desirable future without hunger and malnutrition. It is worth noting that the developed scenario has several limitations. Specifically, colonisation, elitism and anthropocentrism were present in the imagined future. Such limitations were noted by the authors at the end of the process of imagining and presenting the scenario for the readers. This can suggest that the use of creativity in futures thinking and the best intentions by the scenario developers do not necessarily lead to the conceptualization of more or less feasible solutions with no flaws. Undoubtedly useful in uncovering little debated issues and provoking new ideas, a futures perspective about global challenges might benefit from cross-sectorial and more holistic approaches. There is no doubt that food-related challenges are extremely complex. Solutions might be dependent on technological advancements, the idealism and competence of individuals and organisations and, to a greater extent, a radical reconsideration of food production, distribution and consumption systems.

Despite the tourism sector's contribution to the alleviation of food-related issues, it is likely that the eradication of these problems will depend on broader changes that are not limited to the 
transformative potential of tourism experiences. These changes might be based on a radical re-consideration of our economy. Nevertheless, tourism practitioners, including tourism entrepreneurs and private and public food-related organisations, should strive to develop and to support educational food tourism experiences that truly contribute to the many urgent global challenges.

It can be concluded that food tourism can be a valuable context for the discussion and the development of ideas and projects to face the global food-related challenges. With the adoption of an experiential perspective, this can be achieved through the potential of tourism experiences to be a force for change. Transformative tourism experiences can be viewed as the first steps toward the future. As, at the individual level, transformative tourism experiences can contribute to the realisation of the ideal person who a tourist truly wants to be, at the level of our global community, such experiences can bring us closer to SDG 2 (Zero Hunger), as well as SDG 1 (No Poverty) and SDG 2 (Good Health).

\section{References}

Andreescu, L., Gheorghiu, R., Zulean, M. and Curaj, A. (2013), "Understanding normative foresight outcomes: scenario development and the 'veil of ignorance' effect”, Technological Forecasting and Social Change, Vol. 80 No. 4, pp. 711-22.

Baldacchino, G. (2005), "Island entrepreneurs: insights from exceptionally successful knowledge-driven SMEs from 5 European island territories", Journal of Enterprising Culture, Vol. 13 No. 2, pp. 145-70.

Baldacchino, G. (2007), "Islands as novelty sites”, The Geographical Review, Vol. 97 No. 2, pp. 165-74.

Baldacchino, G. (2013), "Island landscapes and European culture: an 'island studies' perspective”, Journal of Marine and Island Cultures, Vol. 2 No. 1, pp. 13-19.

Banks, A. and Banks, S.P. (1998), Fiction and Social Research: By Ice or Fire, AltaMira Press, Walnut Creek, CA.

Bertella, G. (2019), "Sustainability in wildlife tourism: challenging the assumptions and imagining alternatives", Tourism Review, Vol. 74 No. 2, pp. 246-55.

Bina, O., Mateus, S., Pereira, L. and Caffa, A. (2017), "The future imagined: exploring fiction as a means of reflecting on today's grand societal challenges and tomorrow's options”, Futures, Vol. 86, pp. 166-84.

Calás, E., Smircich, L. and Bourne, K.A. (2009), "Extending the boundaries: reframing 'entrepreneurship as social change' through feminist perspectives”, Academy of Management Review, Vol. 34 No. 3, pp. 552-69.

Caraher, M., Lange, T. and Dixon, P. (2000), "The influence of TV and celebrity chefs on public attitudes and behavior among the English public", Journal for the Study of Food and Society, Vol. 4 No. 1, pp. 27-46.

Coghlan, A. and Gooch, M. (2011), "Applying a transformative learning framework to volunteer tourism", Journal of Sustainable Tourism, Vol. 19 No. 6, pp. 713-28.

De Jong, A., Palladino, M., Puig, R.G., Romeo, G., Fava, N., Cafiero, C. and Sjölander-Lindqvist, A. (2018), "Gastronomy tourism: an interdisciplinary literature review of research areas, disciplines, and dynamics", Journal of Gastronomy and Tourism, Vol. 3 No. 2, pp. 131-46.

Descamps, S., Aars, J., Fuglei, E., Kovacs, K.M., Lydersen, C., Pavlova, O. and Strøm, H. (2017), "Climate change impacts on wildlife in a high Arctic archipelago-Svalbard, Norway", Global Change Biology, Vol. 23 No. 2, pp. 490-502.

Dey, P. and Mason, C. (2018), "Overcoming constraints of collective imagination: an inquiry into activist entrepreneuring, disruptive truth-telling and the creation of 'possible worlds'”, Journal of Business Venturing, Vol. 33 No. 1, pp. 84-99.

Eisner, E.W. (1997), "The promise and perils of alternative forms of data representation", Educational Researcher, Vol. 26 No. 6, pp. 4-10.

Ellis, A., Park, E., Kim, S. and Yeoman, I. (2018), "What is food tourism?", Tourism Management, Vol. 68, pp. 250-63.

Falk, J.H., Ballantyne, R., Packer, J. and Benckendorff, P. (2012), "Travel and learning: a neglected tourism research area author links open overlay panel”, Annals of Tourism Research, Vol. 39 No. 2, pp. 908-27. 
FAO (2018), "The future of food and agriculture. Alternative pathways to 2050", FAO, Rome, available at: www.fao.org/3//8429EN/i8429en.pdf (accessed 1 December 2018).

Fennell, D. (2014), "Exploring the boundaries of a new moral order for tourism's global code of ethics: an opinion piece on the position of animals in the tourism industry", Journal of Sustainable Tourism, Vol. 22 No. 7 , pp. 983-96.

Greenhough, B. (2006), "Tales of an island-laboratory: defining the field in geography and science studies", Transactions of Institute of British Geographers, Vol. 31 No. 2, pp. 224-23.

Haugh, H.M. and Talwar, A. (2016), "Linking social entrepreneurship and social change: the mediating role of empowerment”, Journal of Business Ethics, Vol. 133 No. 4, pp. 643-58.

Higgins-Desbiolles, F. (2010), "The elusiveness of sustainability in tourism: the culture-ideology of consumerism and its implications", Tourism \& Hospitality Research, Vol. 10 No. 2, pp. 116-29.

Holt Giménez, E. and Shattuck, A. (2011), "Food crises, food regimes and food movements: rumblings of reform or tides of transformation?", The Journal of Peasant Studies, Vol. 38 No. 1, pp. 109-44.

Hurley, K. (2015), "Envisioning agritourism 2115: organic food, convivial meals, hands in the soil and no flying cars", in Yeoman, I., McMahon-Beattie, U., Fields, K., Albrecht, J.N. and Meethan, K. (Eds), The Future of Food Tourism: Foodies, Experiences, Exclusivity, Visions and Political Capital, Channel View Publications, Bristol, pp. 101-13.

Kelman, I., Burns, T.R. and des Johansson, N.M. (2015), "Islander innovation: a research and action agenda on local responses to global issues", Journal of Marine and Island Cultures, Vol. 4 No. 1, pp. 34-41.

Kirkwood, J. and Walton, S. (2010), "What motivates ecopreneurs to start businesses?", International Journal of Entrepreneurial Behavior \& Research, Vol. 16 No. 3, pp. 204-28.

Lindenfeld, L. (2010), "Can documentary food films like Food Inc. achieve their promise?", Environmental Communication, Vol. 4 No. 3, pp. 378-86.

Linnanen, L. (2005), “An insider's experiences with environmental entrepreneurship”, in Schaper, M. (Ed.), Making Ecopreneurs: Developing Sustainable Entrepreneurship, Gower Publishing, Surrey, pp. 72-88.

Luks, F. (2014), "Theories of 'sustainability' and the sustainability of theories: for alternatives to mainstream, and against simple solutions", in Enders, J.C. and Remig, M. (Eds), Theories of Sustainable Development, Routledge, Oxon, pp. 90-8.

Martin, M. and Brandão, M. (2017), "Evaluating the environmental consequences of Swedish food consumption and dietary choices", Sustainability, Vol. 9 No. 12, pp. 1-21.

Morgan, A.D. (2010), "Journey into transformation: travel to 'other' place as a vehicle for transformative learning”, Journal of Transformative Learning, Vol. 8 No. 4, pp. 246-68.

Moskwa, E., Higgins-Desbiolles, F. and Gifford, S. (2015), "Sustainability through food and conversation: the role of an entrepreneurial restaurateur in fostering engagement with sustainable development issues", Journal of Sustainable Tourism, Vol. 23 No. 1, pp. 126-45.

Phillimore, J. and Goodson, L. (2004), "Progress in qualitative research in tourism", in Phillimore, J. and Goodson, L. (Eds), Qualitative Research in Tourism: Ontologies, Epistemologies, Methodologies, Routledge, London, pp. 21-3.

Pine, B.J. and Gilmore, J.H. (2013), "The experience economy: past, present and future", in Sundbo, J. and Sørensen, F. (Eds), Handbook on the Experience Economy, Edward Elgar, Cheltenham, pp. 21-44.

Pritchard, A., Morgan, N. and Ateljevic, I. (2011), "Hopeful tourism: a new transformative perspective", Annals of Tourism Research, Vol. 38 No. 3, pp. 941-63.

Richardson, L. and St. Pierre, E.A. (2005), "Writing: a method of inquiry", in Denzin, N.K. and Lincoln, Y.S. (Eds), The Sage Handbook of Qualitative Inquiry, Sage Publications, Thousand Oaks, CA, pp. 959-78.

Rindova, V., Barry, D. and Ketchen, D.J. (2009), "Entrepreneuring as emancipation", Academy of Management Review, Vol. 34 No. 3, pp. 477-91.

Robertson, M. and Yeoman, I. (2014), "Signals and signposts of the future: literary festival consumption in 2050", Tourism Recreation Research, Vol. 39 No. 3, pp. 321-42.

Santini, C. (2017), "Ecopreneurship and ecopreneurs: limits, trends and characteristics", Sustainability, Vol. 9 No. 4, pp. 492-503. 
Schaltegger, S. (2002), "A framework for ecopreneurship: leading bioneers and environmental managers to ecopreneurship”, Greener Management International, Vol. 38, Summer, pp. 45-58.

Shepherd, D.A. and Patzelt, H. (2011), "The new field of sustainable entrepreneurship: studying entrepreneurial action linking 'what is to be sustained' with 'what is to be developed'", Entrepreneurship Theory Practice, Vol. 35 No. 1, pp. 137-63.

SSB (2018), "Population of Svalbard”, available at: www.ssb.no/en/befsvalbard/ (accessed 8 January 2019).

Stewart, J.W., Bramble, L. and Ziraldo, D. (2008), "Key challenges in wine and culinary tourism with practical recommendations", International Journal of Contemporary Hospitality Management, Vol. 20 No. 3, pp. 303-12.

Steyaert, C. and Hjorth, D. (2006), Entrepreneurship as Social Change: A Third New Movements in Entrepreneurship, Edward Elgar, Cheltenham.

Stone, M.J. and Petrick, J.F. (2013), "The educational benefits of travel experiences: a literature review", Journal of Travel Research, Vol. 52 No. 6, pp. 731-44.

Stratford, E. (2003), "Flows and boundaries: small islands discourses and challenges of sustainability, community and local environments", Local Environment, Vol. 8 No. 5, pp. 495-9.

Towner, J. (1985), "The grand tour: a key phase in the history of tourism”, Annals of Tourism Research, Vol. 12 No. 3, pp. 297-333.

United Nations (2015), "Transforming our world: the 2030 agenda for sustainable development", available at: www.un.org/ga/search/view_doc.asp?symbol=A/RES/70/1\&Lang=E (accessed 1 December 2018).

United Nations (2018), "About the sustainable development Goals", available at: www.un.org/ sustainabledevelopment/sustainable-development-goals/ (accessed 17 June 2019).

Van Notten, P.W., Rotmans, J., Van Asselt, M.B. and Rothman, D.S. (2003), "An updated scenario typology", Futures, Vol. 35 No. 5, pp. 423-43.

Walley, E.E. and Taylor, D.W. (2002), "Opportunists, champions, mavericks ...?", Greener Management International, Vol. 38, Summer, pp. 31-43.

Wilson, E. and Hollinshead, K. (2015), "Qualitative tourism research: opportunities in the emergent soft sciences", Annals of Tourism Research, Vol. 54, pp. 30-47.

World Health Organization (2018), "Healthy diet, key facts", available at: www.who.int/news-room/factsheets/detail/healthy-diet (accessed 1 December 2018).

Wright, D.W.M. (2018), "Cloning animals for tourism in the year 2070”, Futures, Vol. 95, pp. 58-75.

Yeoman, I. and McMahon-Beatte, U. (2016), "The future of food tourism”, Journal of Tourism Futures, Vol. 2 No. 1, pp. 95-8.

Yeoman, I. and Postma, A. (2014), "Developing an ontological framework for tourism futures", Tourism Recreation Research, Vol. 39 No. 3, pp. 299-304.

\section{Corresponding author}

Giovanna Bertella can be contacted at: giovanna.bertella@uit.no

For instructions on how to order reprints of this article, please visit our website: 